\title{
A Study on the "Flexibility" of Information Systems (Part 3): MIS Flexibility Planning Scheme for IT/Business Strategy Alignment
}

\author{
Masaru Furukawa ${ }^{1}$, Shigeki Hirobayashi ${ }^{2} \&$ Tadanobu Misawa ${ }^{2}$ \\ ${ }^{1}$ Faculty of Economics, University of Toyama, Japan \\ ${ }^{2}$ Graduate School of Science and Engineering, University of Toyama, Japan \\ Correspondence: Masaru Furukawa, University of Toyama, 3190, Gofuku, Toyama-city, Toyama, 930-8555 \\ Japan. Tel: 81-764-456-477. E-mail: frukawa@eco.u-toyama.ac.jp
}

Received: November 22, 2013

Accepted: March 31, 2014

Online Published: May 22, 2014

doi:10.5539/ijbm.v9n6p88

URL: http://dx.doi.org/10.5539/ijbm.v9n6p88

\begin{abstract}
IT/business strategy alignment is still a crucial issue for managers worldwide; how to deal with environmental change has been considered to be the key challenge to strategy alignment. Uncertain and dynamically changing environments require organizations to maintain a high level of alignment with a high risk of IT investment. To maintain this alignment, organizations must learn how to make their management information systems (MISs) sufficiently flexible; therefore, previous studies suggest the importance of MIS flexibility. Nevertheless, there are few studies that explore the practical method of MIS flexibility planning for IT/business strategy alignment. Therefore, Part 1 of this series discusses the meaning of MIS flexibility for this alignment, while Part 2 proposes a scheme to make MISs sufficiently flexible.

The proposed concept of the penalty of change (POC), as a function of cost and time, could bridge the gap between IT and business strategies in practice. This paper presents a scheme for the strategic planning of MIS flexibility by overhauling the IT infrastructure via future-oriented POC analysis. Using this procedure and monitoring the degree of MIS flexibility and alignment in the long term would reduce risks and could transform the corporate MIS into a useful tool to address environmental changes.
\end{abstract}

Keywords: IT/business strategy alignment, strategic information systems planning, MIS flexibility, penalty of change

\section{Introduction}

Nowadays, an organization's success depends heavily on information technology (IT) because many organizations rely on their management information systems (MISs). Nevertheless, organizations, especially their MIS managers, struggle to bridge the huge gap between their business strategy and the IT being implemented to achieve maximumoutput from their MIS. Table 1 illustrates in detail the gap between the MIS division and its corporate end users.

Table 1. Problems faced by the MIS Manager because of the gap in IT/business strategy alignment

\begin{tabular}{ll}
\hline End-user & -We can hardly believe that implementing a new application system will take as long as two \\
(Organization strategy) & $\quad$ years. We cannot wait for such a long time. \\
& - We cannot see why such a small modification will take one month. \\
& - This system does not meet our needs. \\
& - We wish we had a computer of our own in our division. \\
\hline Executive director & - Personnel expenses are increasing too much. \\
(Business strategy) & - It is taking too much time. \\
\hline Engineer & - Why can't we do it ourselves when our competitor is already doing it? \\
(IT strategy) & - Are you telling us to work still harder to develop new systems? \\
& - We already have our hands full with maintenance work. \\
& - Add five more workers, please. \\
& - It takes us at least one year to train a new recruit to become a full-fledged worker. \\
& - Our end-users should just be more cooperative with us. \\
\hline
\end{tabular}

Note. Adapted from Furukawa \& Minami (2013). 
Over the last 50 years, MIS managers have been at the mercy of this gap while seeking to resolve the issue. The literatures suggests that MIS flexibility could be one solution; however, there are few studies on practically employing MIS flexibility planning to align IT and business strategy. Consequently, this paper focuses on the theme of IT/business strategy alignment by means of solving the following question.

How flexible MIS should we acquire to accommodate possible future change demands and when it occurs?

We believe that the answer of this question will alleviate MIS manager's problems.

Part 1 of this series introduces the concept of the penalty of change (POC) as an index of MIS flexibility, and Part 2 proposes a scheme to make MISs flexible by overhauling the infrastructure of corporate MISs via POC analysis. This paper will explore the mechanism of IT/business strategy alignment and then present a practical, strategic planning scheme for MISs whereby a future-oriented POC analysis is employed to overhaul the IT infrastructure. Thus, Section 2 of this paper will review previous studies on IT/business strategy alignment in an uncertain business environment; Section 3 will discuss the link between MIS flexibility and SIS planning; and Section 4 will present the procedures involved in SIS planning: developing MIS flexibility in terms of future-oriented $P O C$ analysis.

\section{Previous Studies on IT/Business Strategy Alignment}

\subsection{Strategy Alignment for an Unpredictable Business Environment}

Every organization has to go through a process of change, since business strategies have to change in response to such instances as foreign exchange fluctuations, price wars, technological innovation, and new products from competitors (Mendelson\& Pillai, 1998). How to deal with these environmental changes has been considered to be the key challenge to strategy alignment (Luftman et al., 1999). An uncertain and dynamically changing environment requires organizations to maintain a high level of alignment with a high risk of IT investment. To maintain this alignment, organizations must learn how to make their MIS sufficiently flexible.

Various factors have been identified in the literature as effective for strategy alignment. Jorfi et al. (2011) claim that the critical factor in creating strategy alignment is IT flexibility, and recommend continuous strategic information system (SIS) planning for monitoring and controlling IT flexibility. In this context, "IT flexibility" refers to the flexibility of the corporate MIS, which facilitates changing its MIS to serve the purposes of the organization; in this paper, it is called "MIS flexibility." Moreover, Part 2 of this series proposes MIS flexibility planning as a practical method to overhaul the IT infrastructure (ITI) in terms of $P O C$ as a function of cost and time, which would bridge the gap between IT and business strategy.

\subsection{MIS Flexibility as a Competitive Factor}

Strategy alignment refers to the extent to which the organization's mission, objectives, and plans support, and are simultaneously supported by, the MIS mission, objectives, and plans (Reich \& Benbasat, 1996). Although a number of significant technologies are emerging, executives still classify strategic alignment and consider it to be the most crucial factor that they confront in their companies (Luftman et al., 2006).

Strategy alignment is essential because of its impact on several aspects of core business performance, and the fact that organizations have to survive in a competitive and rapidly changing business environment (Jorfi, et al., 2011). In other words, the environment compels an organization to make its MIS flexible and quick to respond in order to adapt to predicted and sudden changes; this is MIS flexibility, while quickness to respond is the competitive advantage. Thus, MIS flexibility should be considered to be a competitive factor.

\subsection{MIS Flexibility in an Uncertain Business Environment}

Since the business environment is changing rapidly, organizations have had to change their mindset from the assumption of predictability to one of uncertainty about competition. In this new context, customers have become both competitors and their competitors' partners. Even though business environments have become more complex and are changing dramatically, organizations must still continue "business as usual," including their IT investments to survive in this uncertain environment (Luftman, 1996).

As already mentioned, managers have recognized that change is one of the key challenges in dealing with strategy alignment (Luftman et al., 1999). When an organization revises its objectives, its strategy needs to be altered as well (Porter, 1996). Therefore, the primary challenges for alignment the corporate MIS keeping pace with the changes to be implemented, and the organization planning effectively for its MIS to be able to respond to those changes. Each organization will experience change in its own way. 


\subsection{Effective SIS Planning}

In SIS planning, a critical factor is how to deal with sudden and unpredictable change. To maintain the business strategy and achieve more benefit from the corporate MIS, the ability to be flexible and respond promptly to changes is indispensable (Segars\& Grover, 1999; Tallon et al., 2000; Furukawa \& Minami, 2013). However, the MIS can provide a competitive advantage only if changes to it can be completed in a short time, so that it promotes the business strategy (Bharadwaj, 2000; Furukawa \& Minami, 2013). On the other hand, if changing it takes long, achieving the business strategy will be delayed.

The recent uncertainty in the business environment has resulted in worldwide competition (Friedman, 2006). Consequently, the costs incurred by the lack of alignment have been increasing; and the difficulty of maintaining a high level of alignment has also been increasing (Venkatraman, 1993). Hence, organizations must deal properly with their IT strategy. Nevertheless, organizations tend to pursue short-term profits and avoid long-term IT investment, even though this may be a significant cause of the misalignment (Bharadwaj, 2000). In other words, the complexity of its corporate MIS makes it difficult to support and achieve the organization's revised strategy, i.e., the MIS is incapable of responding quickly to change. Porter (1991) defines strategy as a dynamic response to environmental change. To succeed in their strategy, even when confronting an ever-changing environment, organizations need to maintain a dynamic and high level of alignment between IT and business strategy (Venkatraman, 1993; Sabherwal et al., 2001). To achieve this level of alignment, the MIS must be able to change in a short time. Three types of quickness are therefore indispensable: (a) quick recognition of changes; (b) quick decision-making to deal with these changes; and (c) quick implementation of the chosen countermeasures, which depends on the prompt adjustment of the MIS itself to these countermeasures (Furukawa \& Minami, 2013).

To make SIS planning effective, it is essential for the organization to improve its abilities in recognizing and responding quickly to environmental changes as well as in aligning the corporate MIS with the business strategy (Earl, 1993; Segars \& Grover, 1999). Implementation and subsequent performance will frequently determine the effectiveness of planning (Mintzberg\& Waters, 1985).

\section{Link between MIS Flexibility and SIS Planning}

\subsection{IT Infrastructure as the Source of MIS Flexibility}

Byrd \& Turner (2000) regard flexibility as the degree of ease with which processes and procedures can be changed. Other studies also emphasize the importance of overhauling the ITI to ensure flexibility in supporting customer services, application changes, and organizational connectivity, so as to accommodate environmental changes (Martin \& Leben, 1989; Tallon, 2007). Thus, over half of the IT budgets are spent on overhauling ITI (Weill \& Broadbent, 1998; Gurbaxani, et al., 1998). Carr (2003) claims that the IT budget does not effectively yield business value; on the contrary, from a resource-based perspective, Bharadwaj (2000) claims that the expenditure required for value-generating capacity is much higher than that required for IT. Furthermore, some studies emphasize those features of ITI that enable it to adapt to end-users' requirements (Duncan, 1995), and in order to improve strategic ability, a well-redesigned ITI is indispensable to an organization (Weill et al., 2002).

Generally, the ITI comprises the following: hardware compatibility, software modularity, network connectivity, and IT skills, ensuring that the infrastructure is capable of scaling and evolving easily and quickly in accordance with the requirements of the business environment (Byrd \& Turner, 2000). Serious problems occur, therefore, in cases where hardware is incompatible, networks cannot scale, software cannot be easily customized or changed, and skills are lacking in a particular technology platform. An MIS built on such an ITI cannot promote business flexibility (Duncan, 1995). In addition, the maturity of an organization's MIS architecture is a predictor of the adoption process and operational success (Ross et al., 2006). Thus, the quality of ITI construction should be regarded as a risk factor that could be the cause of $P O C$.

\subsection{Relationship between MIS Flexibility and SIS Planning}

SIS planning is defined as "the process of identifying a portfolio of computer-based applications that will assist an organization in executing its business plans and realizing its business goals" (Hartono et al., 2003). Generally, the objectives of SIS planning are as follows: (1) establishing cooperation between the corporate MIS and business objectives; (2) gaining a competitive edge; (3) managing information resources effectively; and (4) overhauling the ITI and building high-priority applications (Brown, 2004). Previous studies have concluded that the success of MISs is the result of their abilities to recognize and respond quickly to changes and the capabilities for aligning the corporate MIS with business strategy (Earl, 1993; Segars \& Grover, 1999; Furukawa \& Minami, 2013). 
As discussed earlier, previous studies on MIS flexibility indicate that organizations with well-designed ITIs could maintain tight links between IT and business strategy since the ITI is the source of MIS flexibility, which in turn supports changes in business strategy. Repeating the SIS planning procedure could represent exercises for organizations in studying environmental factors that might result in a change in business strategy. In other words, SIS planning is a development process to learn the skill of using IT to respond to changes in the business environment. Thus, experience in SIS planning fosters the ability to harmonize MIS flexibility and business strategy in a positive manner (Jorfi et al., 2011).

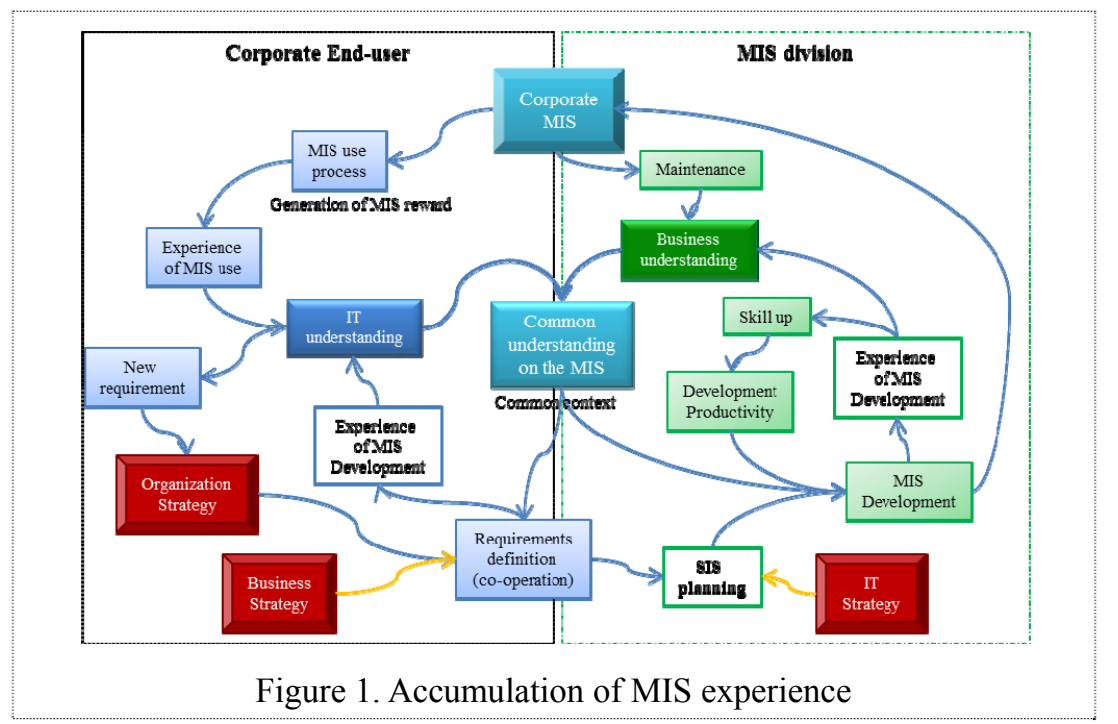

Figure 1 details the process of accumulating MIS experience in a corporation. First, IT begins to be utilized in the corporation, the MIS division leads the development of its corporate MIS, and accumulates experience and an understanding of the business. Then, the initial MIS is provided to corporate end users, and their MIS experience starts. This experience fosters the end users' understanding of IT, resulting in them requesting the MIS division as the source of SIS planning, in order to provide for their new requirements, which also calls for sufficient flexibility. Thus, both IT and business understanding develops a "common understanding on the MIS" and improves the maturity level of IT/business strategy alignment in the corporation.

\subsection{Impact of MIS Flexibility on Strategy Alignment}

The critical challenge for alignment is whether it is possible to provide the business function required by the time the organization intends to change, and how the organization can plan and maintain a quality ITI for quickly responding to changes. Only if this is achieved can the MIS, based on a well-designed ITI, consistently yield benefits.

If MIS serves slow change, because of factors such as legacy systems that are like a tangled thread, or organizational stubbornness, MIS cannot be a source of sustainable profit. In reverse, if MIS serves quick change, organizations can execute their strategy without any constraints from the MIS. The literature suggests that MIS flexibility, with SIS planning, has a positive effect on strategic alignment, and that effective SIS planning comes with experience (Jorfi et al., 2011).

To support an organization in executing and realizing its business mission, objectives, and plans, the MIS should be equipped with the functionality to process information easily and quickly, and therefore be designed without any unwieldy complexity to prevent this. So far, we have explored the simplicity that should be built into MIS flexibility by a proper overhauling of the IT infrastructure.

\section{MIS Flexibility Planning via Future-Oriented POC Analysis}

This section summarizes Parts 1 and 2; it also defines the characteristics of MIS flexibility and demonstrates the necessity to predict future MIS change demands and the way to deal with anticipated change demands by overhauling the IT infrastructure.

\subsection{Definitions of MIS Flexibility via POC}

Here, a precise description of the aforementioned SIS scheme is provided. When the MIS provides an 
application function $(F)$ that is utilized effectively $(U)$, then as a source of competitive advantage that contributes to an organization's performance, it yields usefulness. Such usefulness is defined as a reward (MIS reward) of utilizing the MIS; and so MIS reward is defined as follows:

$$
\text { MIS reward }=f(F, U)
$$

Where $F$ refers to the function of the MIS and $U$ refers to the utilization of $F$.

Regardless of their size, today, most organizations utilize their own MIS, and without it, therefore, no organization can hope for efficient and effective business management. The performance of an organization can thus be defined as a product of the business accomplished because of the utilization of its MIS functions and the cost and time to maintain such functions.

Parker \& Benson (1988) identified ITI as helping to generate MIS value. It is assumed that the contribution of the MIS to an organization's performance is the value of the MIS (MIS Value), which is defined as follows:

$$
\text { MIS value }=\frac{\text { MIS reward }}{g(C, T)}=\frac{f(F, U)}{\text { penalty of change }}
$$

where the denominator $g(C, T)$ is a function of the cost $(C)$ and time $(T)$ to maintain the MIS; $g(C, T)$ can be regarded as a penalty that every MIS manager pays for changing their corporate MIS. The newly yielded value of the MIS (MIS value) increases in proportion to the increase in value of the numerator $f(F, U)$ and/or the decrease in value of the denominator POC. Enhancement of MIS flexibility can satisfy this condition, so that for the present purpose, excluding the numerator allows positing MIS flexibility in the following formula:

$$
\text { MIS flexibilit } y=\frac{1}{\text { penalty of change }}=\frac{1}{P O C}
$$

Note that formula (3) represents the relationship between MIS flexibility and POC: greater MIS flexibility is associated with smaller $P O C$, whereas less MIS flexibility is associated with more POC. Obviously, a larger reward and smaller $(P O C)$ are preferred. Therefore, $P O C$ can be used as an index of MIS flexibility. Enhanced MIS flexibility alleviates the problems described in Table 1 for the MIS manager because a small POC means the MIS can be changed easily and quickly.

\subsection{Probabilistic Definition of POC and MIS Flexibility}

A change is described as the probabilistic event of a transition from a certain state to another (Chryssolouris, 1996). As this idea is helpful to the present purpose, it is used for the POC calculation in the following formula:

$$
P O C=\sum_{i=1}^{n} P O C\left(X_{i}\right) \operatorname{Pr}\left(X_{i}\right)
$$

Where $X_{i}$ is the $i^{\text {th }}$ potential change demand, POC $\left(X_{i}\right)$ is the penalty of $i^{\text {th }}$ in meeting the potential change demand, and $\operatorname{Pr}\left(X_{i}\right)$ is the probability of the $i^{\text {th }}$ potential change demand occurring; $P O C$ is the expected value of the potential changes. However, this, subjective probability is derived from the business strategy and can be taken into account by the MIS division in its decision-making (detailed in Part 1). Therefore, formula (4) is translated into this question:

How flexible should we make our existing MIS to absorb possible future change demands?

In order to seek a more tangible answer, this question can be expressed in the following terms:

How can we properly incorporate factors into our MIS flexibility that will minimize the potential POC, which may be incurred by changing its functionality to absorb possible future demands, when we are proactively redesigning its architecture?

\subsection{Need for Enhanced MIS Performance}

Figure 2 shows the concept of IT/business strategy alignment as described in this paper, and illustrates the relationship between MIS change demands, SIS planning, ITI, and MIS flexibility. 


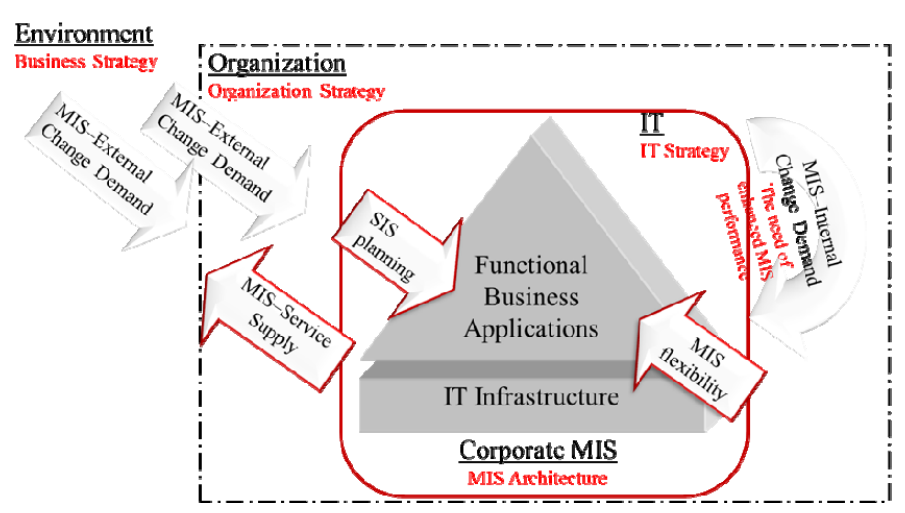

Figure 2. Relationship between MIS change demands, SIS planning, ITI, and MIS flexibility

To acquire MIS value, organizations must address the demands of environmental changes. These demands, which give rise to MIS-external demands, prompt organizations to revise their strategies and incorporate these demands as their business objectives into SIS planning.

To achieve its objectives, an organization needs to enhance its MIS performance and maintain enough MIS flexibility to deal with the MIS-external change demands. This then becomes an additional MIS change demand called the MIS-internal change demand, originating from the IT strategy. The purpose of the IT strategy is to redesign the ITI's architecture, which should enhance MIS flexibility and the ability of the MIS-service supply to provide the necessary functional business applications at the time they are needed.

Needless to say, changes to the MIS require management resources, which should be taken into account by the POC; nevertheless, in reality, these resources are rarely provided. Therefore, it is difficult for the MIS division to process each change demand in the time required, and delays in changes to the MIS can delay the execution of business strategies. Therefore, it is recommended that for the MIS division to break this inappropriate cycle, it must learn how to predict change demands and enhance MIS flexibility so as to manage those demands by redesigning the IT infrastructural with minimal $P O C$. This approach calls for the adaptability of innovative technologies, such as the exchange of IT infrastructural components (Furukawa \& Minami, 2013).

\section{The Planning Scheme for MIS Flexibility}

This section explores the MIS flexibility planning scheme for IT/business strategy alignment by summarizing Furukawa (2001), the original version of Part 2.

\subsection{Construction of MIS Flexibility}

This paper will continue to use the concept of MIS flexibility in the following sense:

How flexible an MIS should we design to accommodate possible future change demands, whenever they occur?

When the MIS division undertakes a change, as illustrated in Figure 2, that demand is more likely to have originated from outside than inside the MIS itself:

- Changes in business strategy to address MIS-external change demands such as changes in laws and institutions.

These change demands have to be executed within a predetermined time.

- Changes in the corporate business process to enhance its performance.

- Changes to the ITI architecture to address MIS-internal change demands such as the MIS division aiming to supply better services to corporate end users.

These changes, with their multiple motivations, should enhance the effectiveness of the existing MIS as well as its capacity to anticipate potential change demands.

\subsection{Significance of Redesigning the IT Infrastructure}

As previously mentioned, an MIS comprises both hardware and software, and is vulnerable to change risks that cause additional cost and time of $P O C$. Thus, each organization has to study and calculate the risk-prone change in hardware and software, its actual risk, and the cost and time of $P O C$ involved to develop evasion strategies, and then all the details shown in Table 2 must be completed. 
Table 2. MIS flexibility and indexes for its evaluation

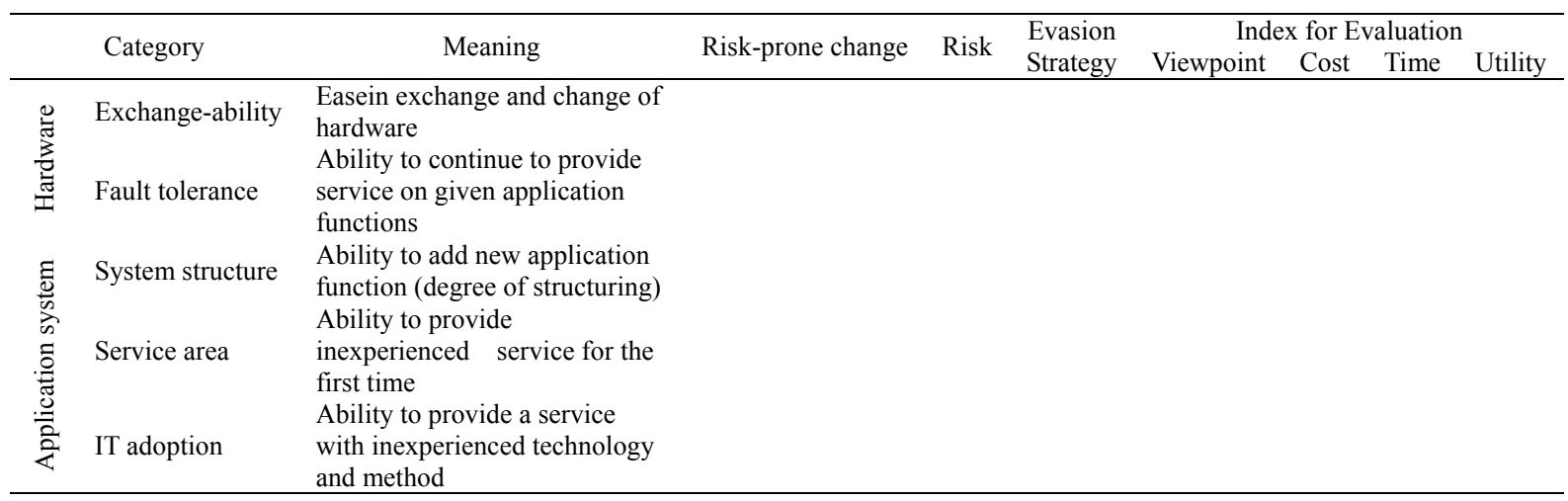

It is well known that a proper redesign of the ITI reduces not only the risks associated with MIS changes but also future $P O C$; however, a redesign incurs additional POC. Furthermore, the MIS division might not be able to obtain adequate resources from its organization to execute the ITI redesign, which explains the reluctance of many MIS divisions to undertake any (Gebauer \& Schober, 2006).

A brief review of the MIS division shows that its major role is to meet the demands for MIS changes from MIS-internal and MIS-external changes with minimum POC. In effect, the division is allowed to incur a minimum $P O C$ to organize the MIS well enough to absorb future change demands. A proper redesign of the ITI can ensure greater ease and efficiency in MIS changes, but it can also incur additional $P O C$ of its own. This fact is represented in the entire structure of MIS flexibility by the $P O C$ index. However, the $P O C$ incurred by a moderate redesign of the ITI can have the benefit of reducing the $P O C$ required to manage future change demands because the redesigned ITI reduces the vulnerability to MIS change. This benefit is referred to as the utility of renovation $\left(U T L_{R}\right)$. Thus, redesigning the ITI can be redefined as the proper application of IT to evade the change risks that accompany MIS changes.

Furthermore, the $P O C$ of an entire MIS change $\left(P O C_{M I S}\right)$ is represented as follows:

$$
P O C_{M I S}=P O C_{S}+\left(P O C_{R}-U T L_{R}\right)
$$

Before proceeding to the answer of the earlier question, defining MIS flexibility in practical terms should be discussed:

How flexible an MIS should we design to accommodate possible future change demands, whenever they occur?

To find an answer, the change demands that are likely to require MIS changes have to be predicted. As previously mentioned, some of these change demands are MIS-external and others are MIS-internal, so the nature of each type needs to be determined, followed by the flexibility characteristics that the MIS should incorporate and develop to address these demands, all in a structured manner.

\subsection{An MIS FlexibilityPlanning Scheme for IT/Business Strategy Alignment}

Figure 3 illustrates an MIS flexibility plan using future-oriented $P O C$ analysis. This process is detailed in Part 2, from which the following abstract is taken:

In Step 1, the MIS-external change demands are predicted from the business and organization strategies, as the sources of MIS change demands. In Step 2, the MIS-external change factors are analyzed by focusing on the "amount of volume of change demands the MIS can accommodate by the required time." Since MIS-external flexibility factors are constrained by MIS-internal flexibility factors, in Step 3, the latter are analyzed by focusing on the "strategies to enhance MIS flexibility" through "selecting the tactics to evade change risks with Table 2." Then, the IT strategy is developed, and if necessary, it will be referred to Step 2. Finally, in Step 4, the optimized SIS plan is selected.

Needless to say, this proposed approach depends much more on the relationship between the organization and technology. Therefore, the value of $P O C$ depends on the capability within an individual organization; low "common understanding on the MIS," as illustrated in Figure 1, will put constraints on executing this approach. In order for an organization to implement this approach, it would have to have accumulated long-term experience, which would foster the ability to construct the calculation basis for the POC. This ability is very much determined by the maturity level of IT/business strategy alignment. 


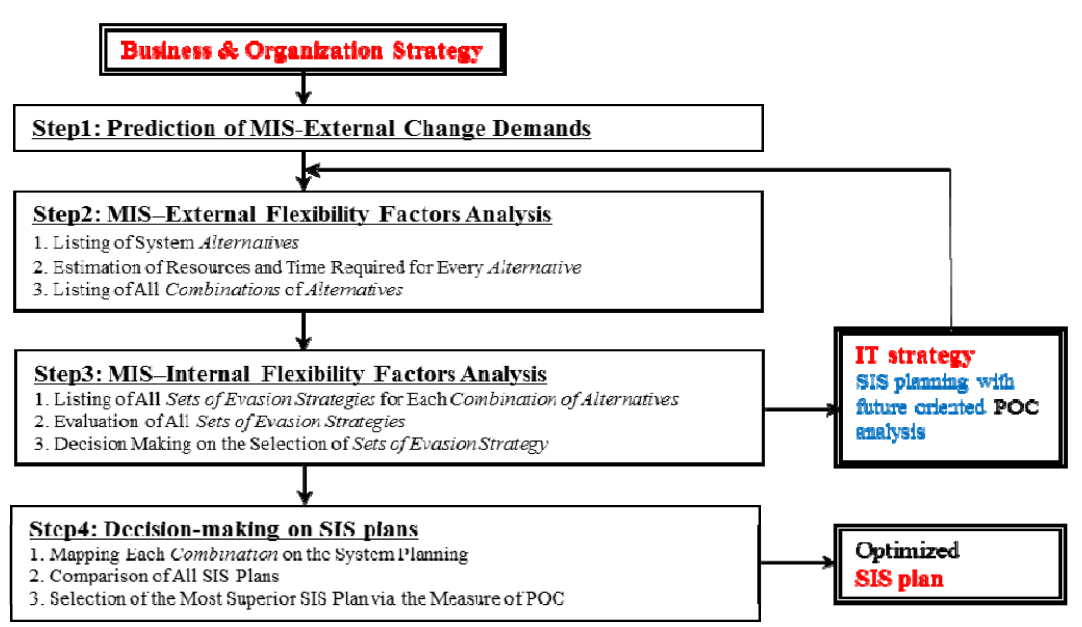

Figure 3. MIS flexibility planning scheme

Note. Revised and adapted from Furukawa (2001).

\section{Discussion}

The proposed scheme is based mainly on the author's experience of MIS development as an engineer, management as a project leader, and a manager of the MIS division in a large company. Thus, the situation illustrated in Table 1 was experienced by the author about 25 years ago.

However, over ten MIS managers have commented on this proposed scheme, and, needless to say, they are still in the same situation as the author was in Table 1.

One of the managers has experience of long-term project management for global MIS development in the Toyota Motor Corporation. Another is a project manager of development, operation, and maintenance for a mission-critical system created in a privatized spin-off from "Post Bank". Their representative assessments are as follows:

After a development project is completed, they always feel a sense of accomplishment, as well as a sense of guilt that they could have built more flexibility into the product.

They have always wanted to build a flexible system, and the proposed scheme links business strategy and IT strategy by means of MIS flexibility. Therefore, they claimed that the proposed scheme would be very useful to practitioners such as themselves when describing and explaining their situation and the importance of MIS flexibility to their executives.

However, two difficulties confront them: one is the difficulty of predicting future change demands that they cannot control; and the other is the inevitable reality that means MIS flexibility is neglected, because the business strategy takes precedence.

In future, more concrete and practical solutions must be found by conducting as many case studies as possible.

\section{Conclusion}

An important and current theme of IT/business strategy alignment has been discussed in this paper, and a planning scheme for MIS flexibility proposed. First, the problem was explained by the gap in IT/business strategy alignment, based on previous studies. Next the link between MIS flexibility and SIS planning was explored, followed by a definition of MIS flexibility via POC analysis, and finally, a description of an MISflexibility planning scheme.

The answer to the question: "How flexible an MIS should we build to accommodate possible future change demands, whenever they occur?" was revealed through the relationship between MIS change demands, SIS planning, ITI, and MIS flexibility as well as indices of evaluation for MIS flexibility contributing to existing knowledge.

The challenges awaiting us are detailed and practical studies on the quantitative relationship between internal and external factors of MIS flexibility. 


\section{References}

Bharadwaj, A. (2000). A resource-based perspective on information technology capability and firm performance: an empirical investigation. MIS Quarterly, 24(1), 169-196. http://dx.doi.org/10.2307/3250983

Brown, I. T. J. (2004). Testing and extending theory in strategic information systems planning through literature analysis. Information Resources Management Journal, 17(4), 20-48. http://dx.doi.org/10.4018/irmj.2004100102

Byrd, T. A., \& Turner, D. E. (2000). Measuring the flexibility of information technology infrastructure: exploratory analysis of a construct. Journal of Management Information Systems, 17(1), 167-208.

Carr, N. (2004). IT doesn't matter. Harvard Business Review, 81(5), 41-49.

Chryssolouris, G. (1996). Flexibility and Its Measurement. CIRP Annals-Manufacturing Technology, 45(2), 581-587. http://dx.doi.org/10.1016/S0007-8506(07)60512-5

Duncan, N. (1995). Capturing flexibility of information technology infrastructure: a study of resource characteristics and their measure. Journal of Management Information Systems, 12(2), 37-57.

Earl, M. J. (1993). Experiences in strategic information systems planning, MIS Quarterly, 17(1), 1-24. http://dx.doi.org/10.2307/249507

Friedman, T. L. (2006). The World Is Flat. New York: Farrar, Straus, and Giroux.

Furukawa, M. (2001). Database Agile Management Dependent on MIS Infrastructure. Informing Science 2001 Conference Proceedings, Krakow, Poland. Retrieved from http://www.proceedings.informingscience.org/IS2001Proceedings/pdf/FurukawaEBKDatab.pdf

Furukawa, M., \& Minami, A. (2013). A Study on the 'Flexibility' of Information Systems (Part 1): Why do they need to be flexible? International Journal of Business and Management, 8(20), 48-61. http://dx.doi.org/10.5539/ijbm.v8n20p48

Furukawa, M. (2013). A Study on the "Flexibility" of Information Systems (Part 2): Howcan We Make Them Flexible? International Journal of Business and Management, 8(19), 73-89. http://dx.doi.org/10.5539/ijbm.v8n19p73

Gebauer, J., \& Schober, F. (2006). Information System Flexibility and the Cost Efficiency of Business Processes. Journal of the Association for Information Systems, 7(3), 122-147. http://aisel.aisnet.org/jais/vol7/iss3/8

Hartono, E., Lederer, A. L., Sethi, V., \& Zhuang, Y. (2003). Key predictors of the implementation of strategic information systems. DATABASE for Advances in Information Systems, 34(3), 41-53. http://dx.doi.org/10.1145/937742.937747

Jorfi, S., M. D., Nor, K., Najjar, L., \& Jorfi, H. (2011). The Impact of IT Flexibility on Strategy alignment (with Focus on Export). International Journal of Business Management, 6(8), 264-271. http://dx.doi.org/10.5539/ijbm.v6n8p264

Luftman, J. N. (1996). Competing in the information age: strategy alignment in practice. New York: Oxford Press.

Luftman, J. N., Papp, R., \& Brier, T. (1999). Enablers and inhibitors of business-IT alignment. Communications of the AIS, 1(11), 1-32. http://aisel.aisnet.org/jais/vol5/iss11/16/

Luftman, J. N., Kempaiah, R., \& Nash, E. (2006). Key issues for IT executives 2005. MIS Quarterly Executive, $5(2), 27-45$.

Martin, J., \& Leben, J. (1989). Strategic Information Planning Methodologies (2nd ed.). Prentice Hall, Inc.

Mendelson, H., \& Pillai, R. R. (1998). Clockspeed and informational response: evidence from the information technology industry. Information Systems Research, 9(4), 415-433. http://dx.doi.org/10.1287/isre.9.4.415

Mintzberg, H., \& Waters, J. A. (1985). Of strategies, deliberate and emergent. Strategic Management Journal, 6(3), 257-272. http://dx.doi.org/10.1002/smj.4250060306

Parker, M. M., \& Benson, R. J. (1988). Information Economics: Linking Business Performance to Information Technology. New Jersey: Prentice Hall.

Porter, M. E. (1991). What is strategy? Harvard Business Review, 74(6), 61-77.

Porter, M. E. (1996). Towards a dynamic theory of strategy. Strategic Management Journal, 12(Winter), 95-117. 
http://dx.doi.org/10.1002/smj.4250121008

Ross, J. W., Weill, P., \& Robertson, D. C. (2006). Enterprise Architecture as Strategy. Cambridge, MA: Harvard Business School Press.

Sabherwal, R., Hirschheim, R., \& Goles, T. (2001). The dynamics of alignment: insights from a punctuated equilibrium model. Organization Science, 12(2), 179-197. http://dx.doi.org/10.1287/orsc.12.2.179.10113

Segars, A. H., \& Grover, V. (1999). Profiles of strategic information systems planning. Information Systems Research, 10(3), 199-232. http://dx.doi.org/10.1287/isre.10.3.199

Tallon, P. P., Kraemer, K. L., \& Gurbaxani, V. (2000). Executives' perceptions of the business value of information technology: a process-oriented approach. Journal of Management Information Systems, 16(4), $145-173$.

Tallon, P. P. (2007). Inside the adaptive enterprise: an information technology capabilities perspective on business. Information Technology and Management, 9(1), 21-36. http://dx.doi.org/10.1007/s10799-007-0024-8

Venkatraman, N., Henderson, J. C., \& Oldach, S. H. (1993). Continuous strategy alignment: exploiting IT capabilities for competitive success. European Management Journal, 11(2), 139-149. http://dx.doi.org/10.1016/0263-2373(93)90037-I

Ward, J., \& Peppard, J. (2007). Strategic Planning for Information Systems (3rd ed.). John Wiley and Sons, Incorporated.

Weill, P., \& Broadbent, M. (1998). Leveraging the New Infrastructure: How Market Leaders Capitalize on Information Technology. Cambridge, MA: Harvard Business School Press.

Weill, P., Subramani, M., \& Broadbent, M. (2002). Building IT infrastructure for strategic agility. Sloan Management Review, 44(1), 57-65.

\section{Copyrights}

Copyright for this article is retained by the author(s), with first publication rights granted to the journal.

This is an open-access article distributed under the terms and conditions of the Creative Commons Attribution license (http://creativecommons.org/licenses/by/3.0/). 